\title{
Prevalence and clinical significance of cardiac murmurs in neonates
}

\author{
Sean B Ainsworth, Jonathan P Wyllie, Christopher Wren
}

\begin{abstract}
Aim-To determine the prevalence and clinical significance of murmurs detected during routine neonatal examination.

Methods-In a two year prospective study, 7204 newborn babies underwent routine examination by senior house officers. All those with murmurs underwent echocardiographic examination. All babies presenting later in infancy were also identified, to ascertain the total prevalence of congenital heart disease in infancy.

Results-Murmurs were detected in 46 babies $(0.6 \%)$ of whom 25 had a cardiac malformation. The most common diagnosis was a ventricular septal defect, although four babies had asymptomatic left heart outflow obstruction. A further 32 infants from the same birth cohort had a normal neonatal examination but were found to have a cardiac malformation before 12 months of age.

Conclusions-The neonatal examination detects only $44 \%$ of cardiac malformations which present in infancy. If a murmur is heard there is a $\mathbf{5 4 \%}$ chance of there being an underlying cardiac malformation. Parents and professionals should be aware that a normal neonatal examination does not preclude a clinically significant cardiac malformation. The detection of a murmur should prompt early referral to a paediatric cardiologist for diagnosis or appropriate reassurance.

(Arch Dis Child Fetal Neonatal Ed 1999;80:F43-F45)
\end{abstract}

Keywords: congenital heart disease; neonatal examination; cardiac murmur; screening

Up to six in every 1000 live born babies have a cardiovascular malformation ${ }^{1}$ which presents in infancy, but most are asymptomatic at birth. $^{1-4}$ Auscultation of the heart during routine examination before discharge from hospital provides an opportunity for early diagnosis and is recommended in the report of the Third Joint Working Party on Child Health Surveillance. ${ }^{5}$ Despite this recommendation, routine auscultation has not been subjected to prospective evaluation.

The difficulties in detecting heart disease at neonatal examination are well known. ${ }^{67}$ The neonatal examination takes place at a time of rapid change within the cardiovascular system as part of adaptation to extra uterine life. ${ }^{8}$ These changes may produce murmurs which can be mistaken for heart disease. ${ }^{9}$ Similarly, if transitional changes are slow to occur, presentation of congenital heart disease may be delayed.
The reported prevalence of murmurs in neonates varies from $0.9 \%$ to $77.4 \%$ and seems to be inversely related to the size of the study. ${ }^{10-19}$ Detection of a murmur depends on the examiner's skill and experience, the timing and frequency of examination, and the conditions under which examination takes place. Most reports of the prevalence of neonatal murmurs come from early studies, ${ }^{10-18}$ predating echocardiography which has improved the accuracy of diagnosis of congenital heart disease. ${ }^{20}$ There is little in published findings that correlates murmurs during the newborn period with confirmed anatomical diagnosis.

This prospective study was undertaken to determine the prevalence and clinical significance of murmurs heard during routine examination of neonates and the contribution of the neonatal examination to detection of congenital heart disease in infancy.

\section{Methods}

The study comprised live born babies at a single large district general hospital between 1 January 1995 and 31 December 1996. Routine examination was undertaken by senior house officers in neonatal paediatrics or obstetrics within 48 hours of delivery. All had received identical training in neonatal examination. Infants who were either premature $(<35$ weeks of gestation) or ill, and who required neonatal intensive care, were excluded from analysis as their examination was not routine. Four cases in which antenatal diagnosis led to termination of pregnancy were also excluded.

Infants with murmurs were re-examined by a consultant (JPW) who performed an echocardiogram, usually within 24 hours of the murmur being heard. Where this was not possible, as in the case of early discharge, babies were brought back to an outpatient clinic or the neonatal unit within two to 14 days.

The echocardiogram permitted early accurate anatomical diagnosis either to reassure parents that the heart was normal, or where heart disease was detected, to explain the nature of the abnormality and, where necessary, to arrange referral for definitive treatment.

Infants who underwent echocardiography were categorised as either having: structural heart malformations; a physiological variant which would account for the murmur (such as left pulmonary artery branch stenosis or patent ductus arteriosus); a finding that in itself would not cause a murmur (such as cardiac hypertrophy secondary to maternal diabetes); or a completely normal echocardiogram. Congenital heart disease was defined as by Mitchell et a ${ }^{1}$ as "a gross structural abnormality of the heart 


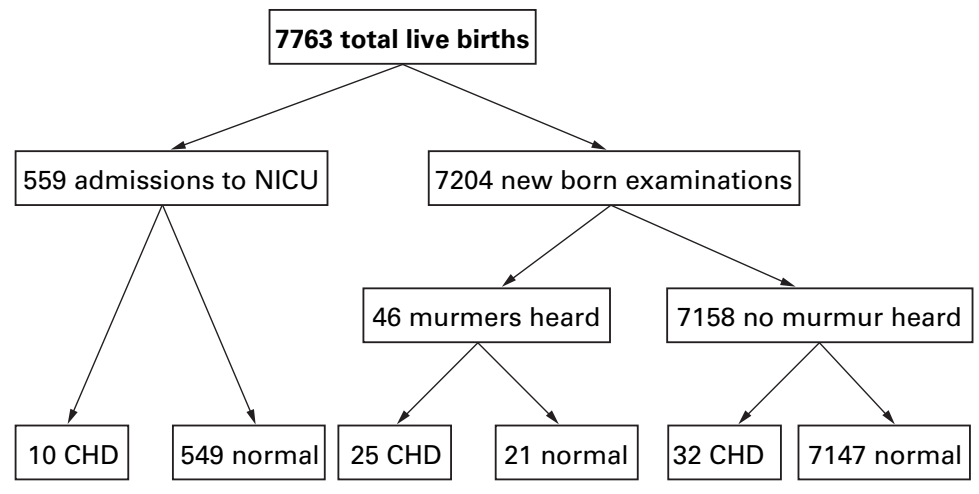

Figure 1 Flow diagram showing progress of all infants included in the study.

Table 1 Anatomical diagnosis and timing of diagnosis

\begin{tabular}{llllllc}
\hline & Antenatal & Early & Intensive care & Newborn & Late & Total (\%) \\
\hline VSD & 0 & 0 & 2 & 15 & 19 & $36(54)$ \\
Complex CHD & 3 & 2 & 0 & 0 & 3 & $8(12)$ \\
Left heart obstruction & 0 & 0 & 0 & 4 & 1 & $5(7)$ \\
Pulmonary stenosis & 0 & 0 & 1 & 1 & 3 & $5(7)$ \\
ASD & 0 & 0 & 1 & 2 & 1 & $4(6)$ \\
Tetralogy of Fallot & 0 & 0 & 0 & 3 & 1 & $4(6)$ \\
ASD/VSD & 0 & 0 & 1 & 0 & 1 & $2(3)$ \\
PDA & 0 & 0 & 0 & 0 & 2 & $2(3)$ \\
TAPVC & 0 & 0 & 0 & 0 & 1 & $1(1)$ \\
Totals & 3 & 2 & 5 & 25 & 32 & $67(100)$ \\
\hline
\end{tabular}

VSD = ventricular septal defect CHD = congenital heart disease ASD = atrial septal defect; $\mathrm{PDA}=$ patent ductus arteriosus; TAPVC $=$ total anomalous pulmonary venous connection.

or intrathoracic great vessels that is actually or potentially of functional importance."

All infants presenting with congenital heart disease during the first year of life from the same birth cohort were identified from the regional paediatric cardiology database. Their hospital records were examined to ensure that murmurs had not been present at the time of the neonatal examination and they had not inadvertently been excluded from early echocardiography.

A randomly selected sample of $400(6 \%)$ case files of infants without heart malformations were scrutinised to ensure no infant with a neonatal murmur had bypassed the study. All senior house officers were informed of the protocol before taking up their post and midwives could not discharge the baby without follow up checks being arranged for any congenital abnormality.

Statistical analysis was limited to calculation of sensitivity and specificity and the intervals of the proportions.

\section{Results}

During the study period, 7763 babies were live born at the hospital (fig 1). Of these, 559 were admitted to the neonatal intensive care unit, including two babies who became symptomatic before routine newborn examination, three known to have cardiac malformations antenatally, and five premature babies who were diagnosed during their stay in intensive care (other

Table 2 Neonatal examination as a screening test

\begin{tabular}{llll}
\hline & Heart disease & No heart disease & Totals \\
\hline Murmur present & 25 & 21 & 46 \\
Murmur absent & 31 & 7127 & 7158 \\
Totals & 56 & 7148 & 7204 \\
\hline
\end{tabular}

\section{Key messages}

- The prevalence of murmurs detected at routine examination of neonates is less than $1 \%$.

- About half of murmurs are due to an underlying cardiovascular malformation

- Early referral of all newborn babies with murmurs for definitive diagnosis is recommended

- The absence of a murmur does not exclude serious heart disease

than patent ductus arteriosus associated with prematurity).

Of 7204 neonates who underwent routine examination, $46(0.6 \%)$ were found to have a murmur (fig 1). All underwent echocardiography which confirmed a cardiac malformation in 25 and a structurally normal heart with physiological findings that would account for the presence of a murmur (such as patent ductus arteriosus or mild physiological pulmonary artery branch stenosis) in eight. Thirteen babies had normal hearts. All 25 babies with cardiac malformations were asymptomatic-15 had a ventricular septal defect, three had coarctation of the aorta, one had aortic valve stenosis, two had an atrial septal defect, one had pulmonary stenosis and three had tetralogy of Fallot (table 1).

A further 32 babies from the same birth cohort presented with congenital cardiac malformations after the routine neonatal examination and before the age of 1 year (table 1 ). Review of the hospital records of these infants confirmed that none had had a murmur at the time of neonatal examination. This identified 25 of 67 cases $(37 \%)$ of structural heart disease diagnosed during infancy. The sensitivity of the examination for detection of congenital heart disease which became apparent during infancy was $44 \%$ (95\% CI $31-58 \%)$, the specificity was $99.7 \%$, and the positive predictive value was $54 \%(95 \%$ CI $39-69 \%)$ (table 2). The high specificity is simply a reflection of the low prevalence in the denominator population.

\section{Discussion}

Although congenital heart disease is present at birth, there are often no signs and most babies are asymptomatic. Detection of a murmur on routine examination may be a clue to the presence of heart disease and offers the possibility of early, presymptomatic diagnosis. Auscultation is, therefore, part of routine neonatal examination and is recommended in Health for All Children. ${ }^{5}$ There is, however, a widespread misconception that murmurs are common in neonates, and that most are innocent or "physiological." This may explain why there seems to be reluctance to make early referral for definitive diagnosis of heart disease. ${ }^{22}$

Most neonatal examinations in the United Kingdom are performed by senior house officers who may see up to 20 babies a day, in conditions that are not ideal for auscultation. Given these limitations it is not surprising that 
the prevalence of murmurs in this study is less than in previous reports. However, this study does reflect real life and its methodology did not change the system it studied. The prevalence of murmurs is consistent with the only previous published study relying on junior medical staff for detection of murmurs. ${ }^{18} \mathrm{We}$ found that murmurs were detected in $0.6 \%$ of babies undergoing routine examination. Fifty four per cent of babies with murmurs had a structural cardiovascular malformation. Most importantly, $9 \%$ of babies with murmurs required early cardiac surgery and were detected before they became symptomatic. This fact, if nothing else, would support the proposition that all babies with murmurs should undergo early paediatric cardiological assessment.

Early assessment of murmurs has been recommended, ${ }^{23}$ but does not always happen. Abu-Harb et al found that 10 of 26 babies with obstructive left heart malformations who had been sent home, despite a murmur at neonatal examination, presented in heart failure before six weeks of age. ${ }^{6}$ Similarly, Beebe et al found that $57 \%$ of neonates dying from cardiovascular malformations after discharge from hospital had had a murmur before discharge. ${ }^{24}$ Thus given that murmurs are rare, and that many are a clue to the presence of asymptomatic heart disease, it seems appropriate to refer all such babies for early definitive diagnosis.

In this study the detection of a murmur at routine neonatal examination led to the diagnosis of $37 \%$ of all cases of congenital heart disease presenting in infancy. Another 15\% presented before examination while $48 \%$ had no murmur and were diagnosed later in infancy. Routine neonatal examination thus has a sensitivity of $44 \%$ and the presence of a murmur has a positive predictive value of $54 \%$. Ascertainment of heart disease was limited to infancy to ensure consistency with the methodology of other recent epidemiological studies. ${ }^{1-322}$ Although neonatal auscultation does not perform particularly well as a screening test, it still offers the only real opportunity of early detection of heart disease. It should, however, be more widely recognised that about half of babies with congenital heart disease will have no signs when examined soon after birth. The low prevalence of murmurs in this study does not mean that murmurs went undetected, but rather that potentially serious heart disease may produce no physical signs early in life. Even in studies with a higher prevalence of murmurs there was no significantly greater detection of heart disease. ${ }^{19}$

The birth prevalence of congenital heart disease diagnosed in infancy in this study ( 9.3 per 1000 life births) is higher than in most large series. ${ }^{1-4}$ This may be explained by a high prevalence of small ventricular septal defects as a result of the easy availability of early echocardiography. Two recent studies using neonatal echocardiography found a prevalence of ventricular septal defect as high as 20 and 53 per 1000 live births. ${ }^{25}{ }^{26}$ In both studies most babies were asymptomatic and most defects were small with early spontaneous closure rates of 76 and $89 \%$, respectively.

This study has shown that a prevalence of murmurs of six in 1000 babies undergoing routine neonatal examination by junior paediatricians. About half of murmurs were due to underlying structural cardiac malformation and this examination led to recognition of $37 \%$ of all heart disease diagnosed in infancy. Identification and treatment of heart disease before development of symptoms offers the prospect of an improved outcome. Early referral of all asymptomatic babies with murmurs is recommended. The absence of a murmur does not exclude the presence of potentially serious heart disease.

The paediatric cardiology database is funded by the Children's Heart Unit Fund.

1 Ferencz C, Rubin JD, McCarter RJ, et al. Congenital heart disease: prevalence at live birth. Am 7 Epidemiol 1985;121:31-6.

2 Grabitz RG, Joffres MR, Collins-Nakai RL. Congenital heart disease: incidence in the first year of life. Am F Epidemiol 1988;128:381-8.

3 Kidd SA, Lancaster PAL, McCredie RM. The incidence of congenital heart defects in the first year of life. $\mathcal{F}$ Paediatr Child Health 1993;29:344-9.

4 Hoffman JIE. Incidence of congenital heart disease: I. Postnatal incidence. Pediatr Cardiol 1995;16;103-13.

5 Hall DMB, ed. Health for all children. Report of the third joint working party on child health surveillance. Oxford: Oxford University Press, 1996.

6 Abu-Harb M, Wyllie J, Hey E, Richmond S, Wren C. Presentation of obstructive left heart malformations in infancy. Arch Dis Child 1994;71;F179-F83.

7 Abu-Harb M, Hey E, Wren C. Death in infancy from unrecognised congenital heart disease. Arch Dis Child $1994 ; 71 ; 3-7$

8 Gandy GM. Examination of the neonate including gestational age assessment. In: Roberton NR, ed. Textbook of Neonatology. 2nd edn. Edinburgh: Churchilll Livinstone, 1992 .

9 Rudolph AM. The changes in the circulation after birth. Circulation 1970;41;343-9.

10 Lyon RA, Rauh LW, Stirling JW. Heart murmurs in newborn infants. F Pediatr 1940;16;310-17.

11 Taylor WC. The incidence and significance of systolic cardiac murmurs in infants. Arch Dis Child 1953;28;52-4.

12 Richards MR, Merritt KK, Samuels MH, Langmann AG. Frequency and significance of cardiac murmurs in the first year of life. Pediatrics 1953;15;169-79.

13 Burnard ED. A murmur from the ductus arteriosus in the newborn baby. BMF 1958;i;806-10.

14 Burnard ED The cardiac murmur in relation to symptoms in the newborn. BMF 1959;i:134-8.

15 Hallidie-Smith KA. Some auscultatory and phonocardiographic findings observed in early infancy. $B M \mathcal{F}$ 1960;i:756-9.

16 Braudo M, Rowe RD. Auscultation of the heart - early neonatal period. Am $\mathcal{F}$ Dis Child 1961;101;67-78.

17 Craige E, Harned HS Jr. Phonocardiographic and electrocardiographic studies in normal newborn infants. Am Heart $\mathcal{f} 1963 ; 65 ; 180-9$.

18 Benson PF, Bonham-Carter RE, Smellie JM. Transient and intermittent murmurs in newborn infants. Lancet intermittent mur

19 Arlettaz R, Archer N, Wilkinson AR. Natural history of innocent murmurs in newborn babies: controlled echocardiographic study. Arch Dis Child 1998;78:F166-F70.

20 Rice MJ, McDonald RW, Reller MD, Sahn DJ. Pediatric echocardiography: Current role and a review of technical advances. F Pediatrics 1996;128:1-14

21 Mitchell SC, Korones SB, Berendes HW. Congenital heart disease in 56109 births. Circulation 1971;43;323-32.

22 Wren C, Richmond S, Donaldson L. Presentation of congenital heart disease in infancy: implications for routine examination. Arch Dis Child 1999;80:F49-53.

23 Silove ED. Assessment and management of congenital heart disease in the newborn by the district paediatrician. Arch Dis Child 1994;70:F71-F4

24 Beebe SA, Britton JR, Britton HL, Fan P, Jepson B. Neonatal mortality and length of newborn hospital stay. Pediatrics 1996:98:231-5.

25 Hiraishi S, Agata Y, Nowatari M, et al. Incidence and natural course of trabecular ventricular septal defect: Twodimensional echocardiography and color Doppler flow imaging study. F Pediatr 1992;120:409-15.

26 Roguin N, Du ZD, Barak M, Nasser N, Hershkowitz S. High prevalence of muscular ventricular septal defect in neonates. F Am Coll Cardiol 1995;26:1545-8. 